\title{
Nilai Total Ketakteraturan Titik dari Honeycomb Network
}

\author{
Corry Corazon Marzuki \\ Jurusan Matematika, Fakultas Sains dan Teknologi, UIN Sultan Syarif Kasim Riau \\ Jl. HR. Soebrantas No. 155 Simpang Baru, Panam, Pekanbaru, 28293 \\ Email: corry@uin-suska.ac.id
}

\begin{abstract}
ABSTRAK
Topik penelitian ini adalah pelabelan total tak teratur titik pada honeycomb network. Misalkan $G=(V, E)$ adalah suatu graf, fungsi $f: V \cup E \rightarrow\{1,2,3, \ldots, k\}$ disebut pelabelan- $k$ total tak teratur titik (vertex irregular total $k$-labeling) pada $G$, jika setiap dua titik yang berbeda di $V$ mempunyai bobot yang berbeda. Bobot titik $x$ di $V$ terhadap fungsi $f$ adalah $w t(x)=f(x)+\sum_{x y \in E} f(x y)$. Bilangan bulat positif terkecil $k$ sedemikian sehingga $G$ mempunyai suatu pelabelan- $k$ total tak teratur titik dinamakan nilai total ketakteraturan titik (total vertex irregularity strength) dari $G$, dilambangkan dengan $\operatorname{tvs}(G)$. Dari hasil penelitian ini diperoleh nilai total ketakteraturan titik dari honeycomb network yang dinotasikan dengan $C H(n)$ untuk $n \geq 2$ adalah $\operatorname{tvs}(C H(n))=\left\lceil\frac{6 n^{2}+2}{4}\right\rceil$.
\end{abstract}

Kata Kunci: pelabelan total, pelabelan-k total tak teratur titik, nilai total ketakteraturan titik, honeycomb network.

\section{ABSTRACT}

Topic of this research is an irregular total labeling, especially a vertex irregular total labeling. Let $G=$ $(V, E)$ is a graph, function $f: V \cup E \rightarrow\{1,2,3, \ldots, k\}$ is called a vertex irregular total $k$-labeling in $G$ if every two distinct vertices in $V$ have different weight. The weight of vertex $x$ in $V$ is $w t(x)=f(x)+\sum_{x y \in E} f(x y)$. The minimum integer $k$ such that $G$ have a vertex irregular total $k$-labeling is called total vertex irregularity strength of $G$, denoted by $\operatorname{tvs}(G)$. From this research we find total vertex irregularity strength of honeycomb network, denotes by $C H(n)$ for $n \geq 2$ is $\operatorname{tvs}(C H(n))=\left\lceil\frac{6 n^{2}+2}{4}\right\rceil$.

Keywords : honeycomb network, total vertex irregularity strength, total labeling, vertex irregular total $k$ labeling.

\section{Pendahuluan}

Menurut Rajasingh dkk. [16], fitur dasar dari suatu sistem adalah komponen-komponen yang terhubung bersama dengan link komunikasi fisik untuk mengirimkan informasi berdasarkan suatu pola tertentu. Dengan kata lain, kekuatan suatu sistem tergantung pada pola koneksi dari komponen sistem tersebut. Suatu pola koneksi dari komponen-komponen pada suatu sistem dikatakan jaringan interkoneksi (interconnection network) atau jaringan (network) dari suatu sistem.

Ada banyak jenis jaringan interkoneksi. Diantaranya ada yang didesain dan ada juga yang diambil dari arsitektur alam. Contoh jaringan interkoneksi yang didesain adalah hypercube, complete binary trees, butterflies, dan torus network. Sedangkan jaringan interkoneksi yang mengikuti arsitektur alam diantaranya grid, hexagonal network, honeycomb network, dan diamond network.

Rajasingh dkk. [16] juga mengatakan bahwa gabungan honeycomb network digunakan secara luas pada industri pesawat terbang. Sedangkan Masuda dkk. [12] dan Gadkaree dkk. [8] mengatakan bahwa perkembangan terkini menunjukkan bahwa struktur honeycomb juga bermanfaat pada aplikasi yang melibatkan susunan nanohole dalam alumina anodized, susunan 
mikro dalam film polymerthin, activated carbon honeycombs dan struktur gap honeycomb pita fotonik.

Pada makalah Rajasingh dkk. [16] disebutkan bahwa kemajuan teknologi sirkuit terpadu berskala besar memungkinkan pembangunan jaringan interkoneksi yang kompleks. Teori graf menyediakan suatu alat dasar untuk mendesain dan menganalisa suatu jaringan. Salah satu hal yang menarik adalah melakukan pelabelan pada jaringan interkoneksi.

Pelabelan graf mempunyai banyak aplikasi yang tersebar dalam berbagai bidang, seperti pada bidang komunikasi, penyimpanan data, pemancar frekuensi radio, jaringan komputer, kristalografi, teori koding, astrologi, skema pembagian rahasia (secret sharing schema), dan radar pulse code. Pada tahun 2001, Wallis [24] telah menerapkan pelabelan total sisi-ajaib pada penentuan alamat dari jaringan komunikasi. Banyaknya aplikasi dari pelabelan graf ini menjadi salah satu penyebab pelabelan graf menjadi suatu topik yang banyak mendapat perhatian.

Misalkan $G=(V, E)$ adalah suatu graf sederhana. Pelabelan graf secara umum didefinisikan sebagai suatu fungsi dari himpunan bagian unsur-unsur dari $G$ ke suatu himpunan bilangan, biasanya himpunan bilangan bulat positif atau non-negatif, yang memenuhi syarat tertentu.

Ditinjau dari unsur graf yang dipetakan, pelabelan graf dibagi menjadi beberapa jenis : pelabelan titik, jika titik-titik graf yang menjadi domain; pelabelan sisi, jika sisi-sisi graf yang menjadi domain; dan pelabelan total, jika yang diberi label adalah titik dan sisi graf. Berdasarkan bobot unsur graf, pelabelan dapat dibedakan menjadi beberapa jenis, antara lain pelabelan anggun (graceful labeling), pelabelan harmonis, pelabelan ajaib (magic labeling), pelabelan anti ajaib (antimagic labeling), dan pelabelan tak teratur (irregular labeling).

Topik penelitian ini adalah pelabelan total tak teratur titik pada honeycomb network. Pada tahun 2007, Baca dkk. [6] mendefinisikan dua jenis pelabelan total tak teratur, yaitu pelabelan total tak teratur sisi dan pelabelan total tak teratur titik. Misalkan $G=(V, E)$ adalah suatu graf, fungsi $f: V \cup E \rightarrow\{1,2,3, \ldots, k\}$ disebut pelabelan- $k$ total tak teratur titik (vertex irregular total $k$ labeling) pada $G$, jika setiap dua titik yang berbeda di $V$ mempunyai bobot yang berbeda. Bobot titik $x$ di $V$ terhadap fungsi $f$ adalah $w t(x)=f(x)+\sum_{x y \in E} f(x y)$. Bilangan bulat positif terkecil $k$ sedemikian sehingga $G$ mempunyai suatu pelabelan- $k$ total tak teratur titik dinamakan nilai total ketakteraturan titik (total vertex irregularity strength) dari $G$, dilambangkan dengan $\operatorname{tvs}(G)$.

Salah satu aplikasi dari pelabelan tak teratur titik ini adalah pada pengaturan frekuensi radio. Permasalahan yang muncul adalah bagaimana agar gelombang sinyal yang digunakan dapat efisien dan tidak terjadi interferensi. Hal ini dapat diatasi menggunakan nilai total ketakteraturan titik karena dengan label sekecil mungkin yang digunakan, diperoleh bobot setiap titik yang berbeda, sehingga tidak ada gelombang radio yang berinterferensi.

Nilai total ketakteraturan titik dari suatu graf ini sangat dipengaruhi oleh pola/struktur grafnya. Oleh karena itu, sangatlah sulit untuk menemukan nilai total ketakteraturan titik untuk sebarang graf secara umum. Sampai saat ini beberapa kelas graf sudah diketahui nilai total ketakteraturan titiknya, diantaranya nilai total ketakteraturan titik dari graf pohon yang didapatkan oleh Nurdin dkk. [14], nilai total ketakteraturan titik dari graf roda terkait dengan beberapa graf yang diperoleh oleh Ahmad dkk. [2], dan nilai total ketakteraturan titik dari gabungan saling lepas graf matahari yang telah ditentukan oleh Slamin dkk. [23]. Kemudian pada tahun 2013, AlMushayt dkk.[4] menentukan nilai total ketakteraturan titik dari convex polytope graph. Pada tahun yang sama, Rajasingh dkk. [17] mendapatkan nilai total ketakteraturan titik dari circulant ladder dan windmill graph.

Penelitian ini terus berkembang setiap tahunnya sampai sekarang. Pada tahun 2017, Aarthi [1] menentukan kestabilan nilai total ketakteraturan titik dari graf helm. Graf helm ialah graf yang dinotasikan dengan $H_{n}$ yang terbentuk dari sebuah graf roda $W_{n}$ dengan penambahan sisi pendant pada setiap titik dari sikel ke- $n$. Pada tahun yang sama, Indriati dkk. [10] mengkonstruksi pelabelan total tak teratur titik, pelabelan total tak teratur sisi, dan pelabelan total tak teratur total untuk graf caterpillar berbentuk khusus. Caterpillar adalah sebuah tree sedemikian sehingga jika 
semua vertex yang berada pada bagian daun dan edge-edgenya yang menempel dihilangkan, graf yang tersisa membentuk suatu lintasan. Pada tahun itu juga, Rajasingh dkk.[16] memperoleh nilai total ketakteraturan sisi dari honeycomb torus network. Kemudian, pada tahun 2018 Ramdani dkk. [20] mendapatkan nilai total ketakteraturan titik untuk graf hasil kali comb dari dua graf lingkaran. Sedangkan Jeyanthy dkk. [11] memperoleh nilai total ketakteraturan titik dari beberapa jenis graf, yaitu cycle quadrilateral snake, sunflower, double wheel, fungus, triangular book, dan quadrilateral book.

Mengingat urgensi dan aplikasi dari pelabelan graf dan jaringan interkoneksi ini, pada makalah ini akan ditentukan nilai total ketakteraturan titik dari salah satu jaringan interkoneksi, yaitu honeycomb network.

\section{Bahan dan Metode Penelitian}

\section{Terminologi Graf}

Berikut akan dijelaskan definisi beberapa istilah pada teori graf, yaitu definisi graf, ketetanggaan, bersisian, dan derajat, serta jenis-jenis graf.

\section{Definisi 1 [7]}

Graf $G$ didefinisikan sebagai triple terurut $\left(V(G), E(G), \varphi_{G}\right)$ dengan $V(G)$ adalah himpunan titik yang tak kosong, $E(G)$ adalah himpunan sisi yang saling lepas dengan himpunan titik $V(G)$, dan $\varphi_{G}$ adalah fungsi insidensi yang mengaitkan setiap sisi pada $G$ dengan pasangan tak terurut titiktitik pada $G$ (tidak harus berbeda). Jika $e$ adalah sisi yang menghubungkan titik $u$ dan $v$, maka ditulis $\varphi_{G}(e)=u v$, dimana $e$ dikatakan join dari $u$ dan $v$, sedangkan titik $u$ dan $v$ dikatakan ujung dari $e$.

Definisi di atas menyatakan bahwa $V$ tidak boleh kosong, sedangkan $E$ boleh kosong.

\section{Definisi 2 [7]}

Ujung dari sebuah sisi dikatakan terkait dengan sisi tersebut. Kedua titik yang terkait dengan sebuah sisi dikatakan bertetangga. Sedangkan dua sisi terkait dengan suatu titik.

\section{Definisi 3 [7]}

Suatu sisi dari suatu titik ke titik itu sendiri dinamakan loop, sedangkan suatu sisi dengan ujung yang berbeda dikatakan link.

\section{Definisi 4 [13]}

Derajat suatu titik pada graf tak berarah adalah jumlah sisi yang bersisian dengan titik tersebut. Derajat titik $v$ dinotasikan dengan $d(v)$.

\section{Jenis Jenis Graf dan Operasi pada Graf}

Graf dapat dikelompokkan menjadi beberapa kategori atau jenis, tergantung pada sudut pandang pengelompokannya. Pengelompokan graf dapat dipandang berdasarkan ada tidaknya sisi ganda atau sisi gelang, berdasarkan jumlah titik atau berdasarkan orientasi arah pada sisi dan berdasarkan struktur.

Munir dkk. [13] membedakan graf menjadi dua jenis berdasarkan ada tidaknya sisi ganda atau sisi gelang pada graf tersebut sebagai berikut :

1. Graf Sederhana (simple graph)

Graf sederhana adalah graf yang tidak mengandung sisi ganda maupun gelang. Pada graf sederhana, sisi adalah pasangan tidak terurut (unordered pairs). Contoh dari graf sederhana dapat dilihat pada Gambar 1. 


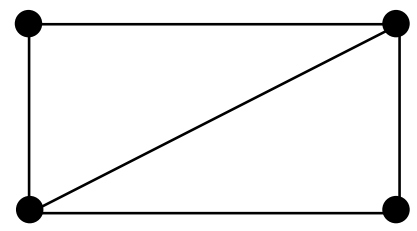

Gambar 1 Graf Sederhana

2. Graf Tak Sederhana (unsimple graph)

Graf yang mengandung sisi ganda atau gelang disebut graf tak sederhana. Graf tak sederhana dibedakan atas dua jenis, yaitu graf ganda (multigraph) dan graf semu (pseudograph). Contoh dari graf tak sederhana dapat dilihat pada Gambar 2.2.

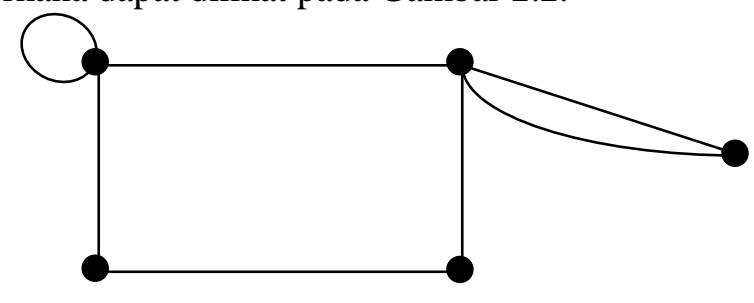

Gambar 2 Graf Tak Sederhana

\section{Honeycomb Network}

Untuk mendesain jaringan interkoneksi langsung, ada tiga teselasi berupa poligon regular yang dapat digunakan sebagai dasarnya, yaitu triangular, square, dan hexagonal. Dengan menggunakan hexagonal, akan didapatkan jaringan interkoneksi berupa honeycomb network. Berikut diberikan definisi dari honeycomb network.

\section{Definisi 5 [17]}

Honeycomb network $H C(r)$ diperoleh dari $H C(r-1)$ dengan menambahkan satu lapis hexagon di sekeliling batas dari $H C(r-1)$. Honeycomb network $H C(1)$ adalah suatu hexagon. Honeycomb network $H C(2)$ diperoleh dengan menambahkan 6 hexagon pada sisi pembatas dari $H C(1)$. Parameter $r$ dari $H C(r)$ menyatakan banyak hexagon antara pusat dan batas dari $H C(r)$.

Karena $H C(r)$ diperoleh dengan menambahkan satu lapis hexagon di sekeliling batas dari $H C(r-$ 1), $H C(r)$ terdiri dari $H C(r-1)$ yang dikelilingi oleh cycle $C(r)$ dengan panjang $12 r-6$ dengan sisi yang menghubungkannya. Banyaknya titik dan sisi dari $H C(r)$ adalah $6 r^{2}$ dan $9 r^{2}-3 r$ secara berurutan.

\section{Pelabelan Graf}

Pelabelan graf pertama kali diperkenalkan oleh matematikawan Sedlacek pada Tahun 1963. Pelabelan graf merupakan pemberian label yang berupa bilangan bulat positif pada elemenelemen dalam graf berupa sisi atau titik.

Pelabelan pada suatu graf adalah pemetaan yang memasangkan unsur-unsur graf (titik/sisi) dengan bilangan bulat positif. Jika domain pemetaan adalah titik, maka disebut pelabelan titik. Jika domain pemetaan adalah sisi, maka disebut pelabelan sisi. Jika domain dari pemetaan adalah titik dan sisi, maka disebut pelabelan total.

Wallis W.D. [24] menyebutkan bahwa bobot (weight) dari elemen graf adalah jumlah dari semua label yang berhubungan dengan elemen graf tersebut. Bobot dari titik $v$ dengan pelabelan $\lambda$ adalah $w t(v)=\lambda(v)+\sum_{u v \in E} \lambda(u v)$. Sedangkan bobot dari sisi $u v$ adalah $w t(u v)=\lambda(u)+$ $\lambda(u v)+\lambda(v)$.

Sampai saat ini terdapat beberapa jenis pelabelan graf yang telah dikaji, salah satunya adalah pelabelan total tak teratur. Pelabelan total tak teratur terdiri dari: pelabelan total tak teratur titik, 
pelabelan total tak teratur sisi dan pelabelan total tak teratur total. Berikut akan dijelaskan mengenai pelabelan total tak teratur titik yang didefinisikan oleh Bača, dkk. pada Tahun 2007 dalam makalahnya yang berjudul "On Irregular Total Labelling".

\section{Definisi 6 [6]}

Misalkan $G=(V, E)$, pelabelan- $k$ total didefinisikan sebagai pemetaan

$$
\lambda: \mathrm{V} \cup \mathrm{E} \rightarrow\{1,2, \ldots, k\} .
$$

Pelabelan- $k$ total dikatakan sebagai pelabelan- $k$ total tak teratur titik dari graf $G$ jika untuk setiap titik $x$ dan $y$ yang berbeda maka $w t(x) \neq w t(y)$.

Adapun $w t(x)$ merupakan bobot titik $x$ yang dinyatakan sebagai:

$$
w t(x)=\lambda(x)+\sum_{u x \in E} \lambda(u x)
$$

Nilai total ketakteraturan titik (total vertex irregularity strength) graf $G$ dinotasikan dengan $\operatorname{tvs}(G)$ adalah nilai $k$ minimum atau label terbesar minimum yang digunakan untuk melabeli graf $G$ dengan pelabelan total tak teratur titik.

Baca dkk. (2007) juga menunjukkan batas bawah dan batas atas dari nilai total ketakteraturan titik untuk sebarang graf.

\section{Teorema $7[6]$}

Misalkan $G$ adalah graf $(p, q)$ dengan titik $p=p(G)$ dan sisi $q=q(G)$, derajat minimum $\delta=\delta(G)$ dan derajat maksimum $\Delta=\Delta(G)$, maka $\left\lceil\frac{p+\delta}{\Delta+1}\right\rceil \leq t v s(G) \leq p+\Delta-2 \delta+1$.

Kemudian pada tahun 2009, Anholcer dkk. memberikan batas atas dari nilai total ketakteraturan titik yang lebih ketat, seperti yang dinyatakan pada teorema berikut.

\section{Teorema 8 [5]}

Misalkan $G$ adalah suatu graf berorde $n$ dengan derajat minimum $\delta>0$. Maka $\operatorname{tvs}(G) \leq 3\left\lceil\frac{n}{\delta}\right\rceil+$ 1.

Kemudian pada tahun 2010, Nurdin dkk. memberikan batas bawah yang lebih ketat untuk sebarang graf terhubung, seperti dinyatakan pada teorema berikut.

\section{Teorema 9 [15]}

Misalkan $G$ adalah suatu graf terhubung yang mempunyai $n_{i}$ titik yang berderajat $i(i=\delta, \delta+$ $1, \delta+2, \ldots, \Delta$ ) dimana $\delta$ dan $\Delta$ adalah derajat minimum dan maksimum dari $G$, secara berurutan. $\operatorname{Maka} t v s(G) \geq \max \left\{\left[\frac{\delta+n_{\delta}}{\delta+1}\right],\left[\frac{\delta+n_{\delta}+n_{\delta+1}}{\delta+2}\right], \ldots,\left[\frac{\delta+\sum_{i=\delta}^{\Delta} n_{i}}{\Delta+1}\right]\right\}$.

Berikut diberikan beberapa nilai total ketakteraturan titik dari beberapa graf, yaitu graf caterpillar, circulan ladder, dan windmill.

\section{Teorema 10 [10]}

Misalkan $S_{n, 2, m}$ adalah suatu graf caterpillar dengan $n, m \geq 3$. Nilai total ketakteraturan titiknya adalah:

$$
\operatorname{tvs}(G) \leq\left\lceil\frac{n+m-1}{2}\right\rceil
$$




\section{Teorema $11[16]$}

Nilai total ketakteraturan titik dari graf circulan ladder adalah $\operatorname{tvs}(C L(n))=\left\lceil\frac{2 n+3}{4}\right\rceil$.

\section{Teorema 12 [16]}

Nilai total ketakteraturan titik dari windmill graph adalah $\operatorname{tvs}\left(C_{3}^{(m)}\right)=\left\lceil\frac{2 m+2}{3}\right\rceil$.

\section{Hasil dan Pembahasan}

Berikut diberikan sebuah teorema mengenai nilai total ketakteraturan titik dari graf $H C(n)$ beserta pembuktiannya. Teorema ini diperoleh dengan pertama kali menentukan batas bawah dari nilai total ketakteraturan titik dari graf $H C(n)$ menggunakan Teorema 7, kemudian dikonstruksi pelabelan total tak teratur total dari graf $H C(n)$ untuk $n=2,3,4,5$. Berdasarkan pola pelabelan total tak teratur total dari graf $H C(n)$ tersebut dirumuskan pelabelan total tak teratur total dari graf $H C(n)$ untuk $n \geq 2$. Dengan adanya pelabelan tersebut, maka terbuktilah bahwa batas bawah dari nilai total ketakteraturan titik dari graf $H C(n)$ tersebut juga merupakan batas atasnya. Sehingga diperoleh nilai total ketakteraturan titik dari graf $H C(n)$ seperti pada Teorema 13 berikut.

Teorema 13 Misalkan $H C(n)$ adalah graf honeycomb network level $n$. Nilai total ketakteraturan titik dari graf $H C(n)$ untuk $n \geq 2$ adalah

$$
\operatorname{tvs}(H C(n))=\left\lceil\frac{6 n^{2}+2}{4}\right\rceil
$$

\section{Bukti:}

Perhatikan bahwa banyaknya titik dari $H C(n)$ adalah $6 n^{2}$, derajat titik minimum pada graf $H C(n)$ adalah 2 dan derajat titik maksimum dari $H C(n)$ adalah 3. Oleh karena itu, berdasarkan Teorema 7 diperoleh bahwa $\operatorname{tvs}(H C(n)) \geq\left\lceil\frac{6 n^{2}+2}{4}\right\rceil$. Sekarang akan dibuktikan bahwa $\operatorname{tvs}(H C(n)) \leq\left\lceil\frac{6 n^{2}+2}{4}\right\rceil$. Hal ini akan dibuktikan dengan menunjukkan adanya pelabelan total tak teratur titik pada $H C(n)$ dengan label terbesarnya $\left\lceil\frac{6 n^{2}+2}{4}\right\rceil$.

Berikut didefinisikan pelabelan- $\left[\frac{6 n^{2}+2}{4}\right]$ total tak teratur titik pada $H C(n)$. Misalkan $k=\left\lceil\frac{6 n^{2}+2}{4}\right]$. Definisikan $f: V \cup E \rightarrow\{1,2, \ldots, k\}$ dengan:

a. Pelabelan titik

$$
\begin{gathered}
f\left(v_{6 n^{2}-5}\right)=\left\lfloor\frac{6 n^{2}-3-k}{3}\right\rfloor \\
f\left(v_{i}\right)=\left\{\begin{array}{l}
\left\lceil\frac{i+2-k}{3} \mid ; \text { jika } i-k \equiv 0(\bmod 3) \text { dan } 6 n^{2}-4 \leq i \leq 6 n^{2}\right. \\
\left\lceil\frac{i+2-k}{3}\right\rfloor ; \text { jika } i-k \neq 0(\bmod 3) \text { dan } 6 n^{2}-4 \leq i \leq 6 n^{2}
\end{array}\right. \\
f\left(v_{i}\right)=\left\{\begin{array}{l}
{\left[\frac{i+2}{3}\right\rceil ; j i k a ~ i \equiv 0(\bmod 3) \text { dan } 1 \leq i \leq 6 n} \\
\left\lfloor\frac{i+2}{3}\right\rfloor ; \text { jika } i \neq 0(\bmod 3) \text { dan } 1 \leq i \leq 6 n
\end{array}\right.
\end{gathered}
$$

b. Pelabelan sisi

$$
\begin{gathered}
f\left(v_{1} v_{3}\right)=1 \\
f\left(v_{2} v_{6 n+1}\right)=1
\end{gathered}
$$




$$
\begin{aligned}
& f\left(v_{i} v_{6 n+i}\right)=\left\lceil\frac{i+2}{3}\right\rceil ; \text { untuk } 1 \leq i \leq 2 n-1 \text { dan } i \neq 2 n-2 \\
& f\left(v_{i} v_{6 n+i-2}\right)=\left\{\begin{array}{c}
\left\lfloor\frac{i+2}{3}\right\rfloor ; \text { jika } 4 \leq i \leq 2 n+1 \text { dan } i \neq 2 n \\
\left\lceil\frac{i+2}{3}\right\rceil ; \text { jika } 2 n \leq i \leq 4 n-1 \text { dan } i \neq 2 n+1 \text { dan } i \neq 4 n-2
\end{array}\right. \\
& f\left(v_{i} v_{6 n+i-4}\right)=\left\{\begin{array}{c}
\left\lfloor\frac{i+2}{3}\right\rfloor ; \text { jika } 2 n+2 \leq i \leq 4 n+1 \text { dan } i \neq 2 n+3 \text { dan } i \neq 4 n \\
\left\lceil\frac{i+2}{3}\right\rceil ; \text { jika } 4 n \leq i \leq 6 n-3 \text { dan } i \neq 4 n+1
\end{array}\right. \\
& f\left(v_{i} v_{6 n+i-6}\right)=\left\lceil\frac{i+2}{3}\right\rceil ; \text { untuk } 4 n+2 \leq i \leq 6 n-1 \text { dan } i \neq 4 n-3 \\
& f\left(v_{i} v_{i+2}\right)=\left\lceil\frac{i+2}{3}\right\rceil ; \text { untuk } i=2 n-2,2 n+1,4 n-2,4 n+1,6 n-2 \\
& f\left(v_{6 n-1} v_{12 n-6}\right)=\left\lceil\frac{6 n+1}{3}\right\rceil \\
& f\left(v_{i} v_{i-6}\right)=k ; \text { untuk } 6 n^{2}-5 \leq i \leq 6 n^{2} \\
& f\left(v_{i} v_{i+1}\right)=\left\lceil\frac{i+2-k}{3}\right\rceil ; \text { untuk } 6 n^{2}-5 \leq i \leq 6 n^{2}-1 \\
& f\left(v_{6 n+1+12 \sum_{i=1}^{j}(n-i)} v_{6 n+1+12 \sum_{i=1}^{j}(n-i)+6(n-j-1)}\right)=k-\left\lceil\frac{6(n-j)^{2}+2}{4}\right\rceil+3(n-j) ; \text { untuk } j \\
& =1,2, \ldots, n-4 \\
& f\left(v_{6 n+1+12 \sum_{i=1}^{n-3}(n-i)} v_{6 n+1+12 \sum_{i=1}^{n-3}(n-i)+6.2}\right)=k-6 \\
& f\left(v_{6 n+1+12 \sum_{i=1}^{n-2}(n-i)} v_{6 n+1+12 \sum_{i=1}^{n-2}(n-i)+6}\right)=k
\end{aligned}
$$

Setelah semua titik dan sisi tersebut dilabeli, labeli titik dan sisi yang tersisa sedemikian sehingga bobot titik $v_{i}$ sama dengan $i+2$.

Perhatikan bahwa $f: V \cup E \rightarrow\{1,2, \ldots, k\}$ dengan setiap titik dalam pelabelan total tak teratur titik pada graf $C H(n)$ memiliki bobot yang berbeda. Dapat disimpulkan bahwa $t v s(C H(n)) \leq\left\lceil\frac{6 n^{2}+2}{4}\right\rceil$. Berdasarkan paparan di atas diperoleh bahwa $\operatorname{tvs}(C H(n)) \geq\left\lceil\frac{6 n^{2}+2}{4}\right\rceil$ dan $\operatorname{tvs}(C H(n)) \leq\left\lceil\frac{6 n^{2}+2}{4}\right\rceil$. Jadi terbukti bahwa $\operatorname{tvs}(C H(n))=\left\lceil\frac{6 n^{2}+2}{4}\right\rceil$.

Sebagai ilustrasi dari teorema di atas, diberikan contoh pelabelan total tak teratur titik untuk graf $C H(6)$ dengan $\operatorname{tvs}(C H(6))=\left\lceil\frac{6.6^{2}+2}{4}\right\rceil=55$. Pelabelan tersebut dinyatakan pada Gambar 4 berikut. 


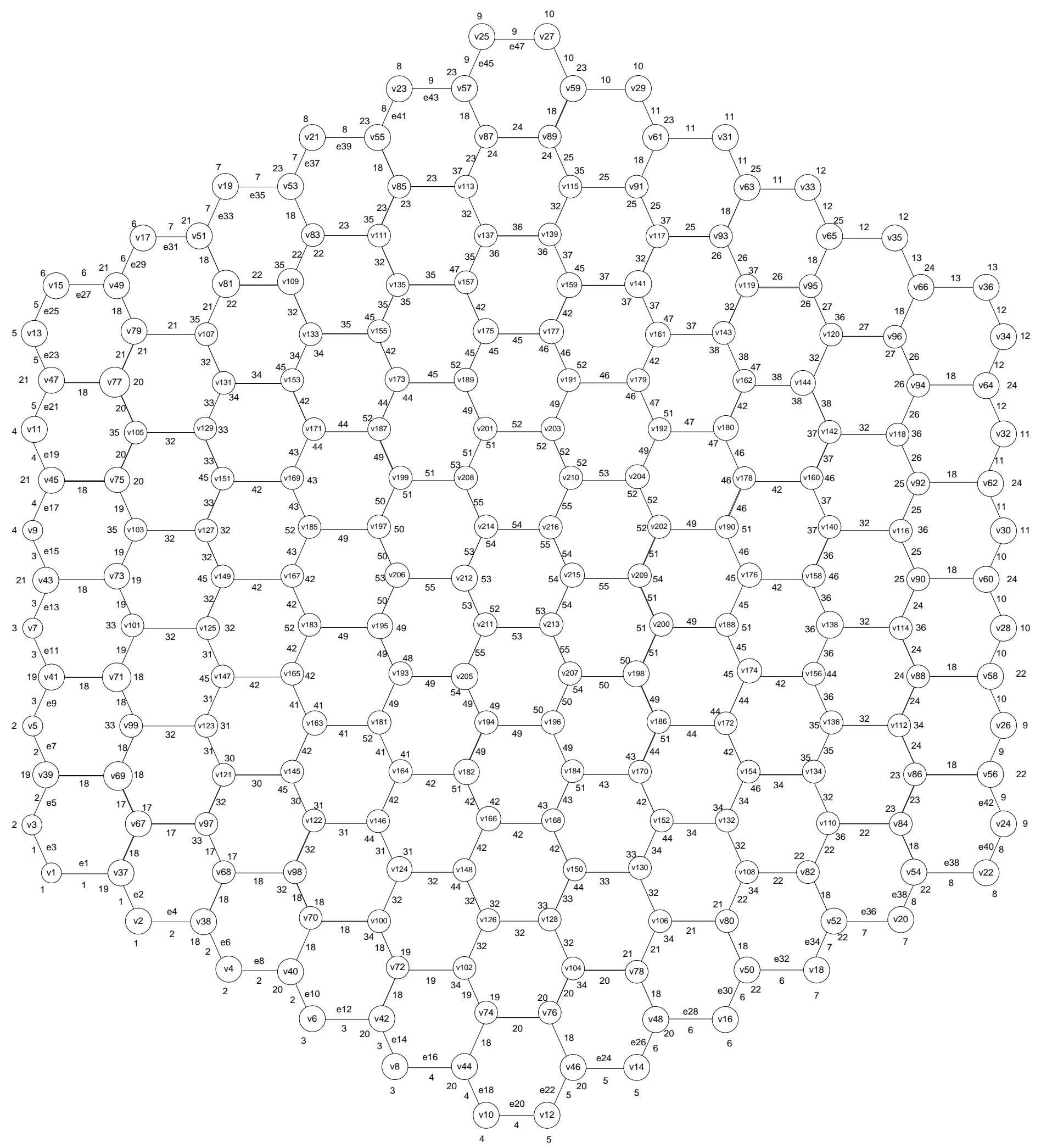

Gambar 4 Pelabelan-55 Total Tak Teratur Titik pada Graf $\mathrm{CH}$ (6) 


\section{Kesimpulan}

Nilai total ketakteraturan titik pada graf $C H(n)$ untuk $n \geq 2$ adalah $\operatorname{tvs}(C H(n))=$ $\left\lceil\frac{6 n^{2}+2}{4}\right\rceil$. Hal ini sudah dibuktikan pada Teorema 13 dengan cara membuktikan bahwa $\left\lceil\frac{6 n^{2}+2}{4}\right\rceil$ merupakan batas bawah dan juga batas atas dari nilai total ketakteraturan titik pada graf $\mathrm{CH}(n)$.

\section{Daftar Pustaka}

[1] Aarthi, S., Stability of Total Vertex Irregularity Strength of Helm Graphs, International Journal of Engineering Science and Computing, 7 (8), 2017. 14599 - 14601.

[2] Ahmad, A., Awan, K.M., Javaid, I., Total Vertex Irregularity Strength of Wheel Related Graphs, Australian Journal of Combinatorics, 51, 2011. 147-156.

[3] Ahmad, A., Baca, M., dan Bashir, Y., Total Vertex Irregularity Strength of Certain Classes of Unicyclic Graphs, Bull. Math. Soc. Sci. Math. Roumanie Tome 57, 105(2), 2014. 147-152..

[4] Al-Mushayt, O., Arshad, A., dan Siddiqui, M.K., Total Vertex Irregularity Strengh of Convex Polytope Graphs, Acta Math. Univ. Comenianae, LXXXII(1), 2013. 29-37.

[5] Anholcer, M., Kalkowski, M., M., Przybylo, J., A New Upper Bound for Total Vertex Irregularity Strength of Graphs, Discrete Mathematics 309, 2009. 6316-6317.

[6] Baca, M., Jendrol, S., Miller, M., Ryan, J., On Irregular Total Labelings, Discrete Math., 307, 2007. 1378-1388.

[7] Bondy, J.A., U.S.R. Murty, Graph Theory with Application, Elsevier Science Publishing Company Inc., New York. 1982.

[8] Gadkaree, K.P., Carbon Honeycomb Structures for Adsorption Applications, Carbon, 36(7), 1998. 981-989.

[9] Gallian, J. A., A Dynamic Survey of Graph Labeling. Electronic Journal of Combinatorics, \#DS6. 2016.

[10] Indriati, D., Widodo, Rosyida, I., dan Sugeng, K.A., The Construction of Labeling and Total Irregularity Strength of Specified Caterpilar Graph, Journal of Physics : Conf. Series 855, 2017.

[11] Jeyanthi, P. dan Sudha, A., Total Vertex Irregularity Strength of Some Graphs, Palestine Journal of Mathematics, 7 (2), 2018. 725-733.

[12] Masuda, H. dan Fukuda, K., Ordered Metal Nanohole Arrays Made by a Two-Step Replication of Honeycomb Structures of Anodic Alumina, Science, 268 (5216), 1995. 1466-1468.

[13] Munir, Rinaldi, Matematika Diskrit Edisi Ketiga. Bandung: Penerbit Informatika. 2010.

[14] Nurdin, Baskoro, E.T., Salman, A.N.M., Gaos, N., On the Total Vertex Irregularity Strength of Trees, Discrete Mathematics 310, 2010. 3043-3048.

[15] Nurdin, Baskoro, E.T., Salman, A.N.M., dan Gaos, N.N., On the Total Vertex-Irregular Labelings for Several Types of Trees, Utilitas Math., 82, 2010. 277-290.

[16] Rajasingh, I. dan Arockiamary, S.T., Total Edge Irregularity Strength of Honeycomb Torus Networks, Global Journal of Pure and Applied Mathematics, 13(4), 2017. 1135-1142.

[17] Rajasingh, I., Rajan, B., dan Annamma, V., Total Vertex Irregularity Strength of Circular Ladder and Windmill Graphs, International Conf. on Mathematical Computer Engineering, 2013. 418-423

[18] Ramdani, R., Salman, A.N.M., Assiyatun, H., An Upper Bound on the Total Vertex Irregularity Strength of the Cartesian Product of $P_{2}$ and an Arbitrary Regular Graph, Procedia Computer Science 74, 2015. 105-111.

[19] Ramdani, R., Salman, A.N.M., Assiyatun H., Semanicova-Fenovcicova, dan Baca, M., On the Total Irregularity Strength of Disjoint Union of Arbitrary Graphs, Math. Reports, 18 (68) 4, 2016. 469-482.

[20] Ramdani, R., dan Ramdhani, M.A., Total Vertex Irregularity Strength of Comb Product of Two Cycles, MATEC Web of Conf. 197, 01007, 2018.

[21] Sari, M., Nilai Total Ketakteraturan dari Graf Butterfly Network Level 3, skripsi.

[22] Silaban, D.R., Kekaleniate, H., Lutpiah, S., Sugeng, K.A., dan Baskoro, E.T., Algorithm to Construct Graph with Total Vertex Irregularity Strength Two, Procedia Computer Science 74, 2015. 132-137.

[23] Slamin, Dafik, dan Winnona, W., Total Vertex Irregularity Strength of Disjoint Union of Sun Graphs, International Journal of Combinatorics , 2012.

[24] Wallis W.D., Magic Graphs, Boston: Birkhauser. 2001. 